\title{
Physical Scaling of Water Mist Suppression of Pool Fires in Enclosures
}

\author{
HONG-ZENG YU \\ FM Global \\ 1151 Boston-Providence Turnpike \\ Norwood, MA 02062
}

\begin{abstract}
A series of fire suppression experiments was conducted in two geometrically similar enclosures of 1:3 ratio to evaluate whether the Froude-modeling-based scaling methodology could reasonably reproduce the pool fire development under water mist application in different scales. The parameters considered in the evaluation were: enclosure size, door opening size, water mist spray condition, fire size, fire location and fire-shielding condition. The two enclosures measured $1.22 \times 1.22 \times 1.22 \mathrm{~m}$ and $3.66 \times 3.66 \times 3.66 \mathrm{~m}$. Two door opening sizes were tested for each enclosure: $0.30 \times 0.61 \mathrm{~m}$ high and $0.61 \times 0.61 \mathrm{~m}$ for the Scale- 1 enclosure, and $0.91 \times 1.83 \mathrm{~m}$ high and $1.83 \times 1.83 \mathrm{~m}$ for the Scale- 3 enclosure. Two heptane fire sizes were selected for each enclosure. The quasi-steady heat release rates of the two pool fires for the Scale- 1 enclosure were 25 and $57 \mathrm{~kW}$, and the corresponding heat release rates were 380 and $860 \mathrm{~kW}$ for the two pool fires used in the Scale3 experiments. Besides matching the quasi-steady heat release rates according to the scaling requirement, the fire developments under free-burn were also carefully scaled. Two water mist nozzles were used to produce the water mist sprays in the Scale-1 and Scale-3 enclosures; these two nozzles were operated at the designated pressures of 13.8 bar and 41.4 bar, respectively. In each enclosure, nine ceiling-mounted nozzles were arranged in a $3 \times 3$ pattern with equal nozzle-to-nozzle and nozzle-to-wall spacing. The experiments showed that the fire development in terms of heat release rate could be reasonably reproduced during free-burn and water mist application in the Scale-1 and Scale-3 enclosures, as well as the oxygen concentration inside the enclosure.
\end{abstract}

KEYWORDS: modeling, suppression, compartment fires, heat release rate, water mist.

\section{INTRODUCTION}

The phenomenon of water mist fire suppression is quite complex [1]. Although numerical simulations of water mist fire suppression [2-4] are valuable in providing engineering guidance, these models have not been sufficiently validated, especially for condensed fuels. Thus, the fire protection industry still heavily relies on the expensive large-scale testing approach to develop water mist fire protection systems. This makes the development of many potential applications economically prohibitive. Until the numerical modeling approach becomes sufficiently mature, a possible interim solution is a proven physical scaling protocol that allows the system development to be performed in a more affordable scaled-down manner. A validated scaling tool is also useful in reducing the computational resource demand by numerical simulations of water-based fire suppression in large occupancies by conducting simulations for, and validation experiments in, a scaled-down facility.

For fire suppression employing water sprays, the suppression result is strongly influenced by the spray pattern and gas flow field resulting from the interaction of water sprays and fire plumes. The spray pattern determines the distribution of water droplets in the gas medium and the distribution of water fluxes realized on the combustible surfaces. The air-borne water droplets can extinguish flames with sufficiently high droplet concentration and small droplet size [5,6], and sufficient water fluxes realized on the burning surfaces can suppress the fires at their origin [7]. It is well known that an aerodynamically-stretched flame is easier to extinguish [8,9]. It has been shown that, as the shear exerted on the flames increases, the required water mist flux for flame extinction decreases [10]. Therefore, it is expected that the fire suppression result can be reasonably reproduced in different physical scales if we can reasonably scale the water-spray-fire-plume interaction.

Froude modeling first requires that, for the fire itself, the ratio of the inertia force of the fire-induced gas flow versus the buoyancy force, i.e. the Froude number, be conserved in different physical scales. The effect of water sprays is then implemented in the modeling by conserving the characteristics of momentum transfer between water droplets and gas flow, and droplet vaporization in the scaled control volume. Based on the 
above requirements, Heskestad derived a set of scaling relationships for the spray-plume interaction intended for fire sprinkler applications [11], where the water droplets in the spray typically have a significant inertia relative to the surrounding gas. Under such a high droplet Reynolds number condition, the droplet size is required to scale with $1 / 2$-power of the scale ratio [11]. However, for the case of water mist, the much smaller droplets tend to move closely with the gas current, leading to low drop Reynolds number situations. Theoretical analysis showed that, under this low Reynolds number condition, the droplet should be scaled with $1 / 4$-power of the scale ratio [12], instead of the aforementioned 1/2-power. The set of scaling relationships with the 1/4-power requirement for droplet size has been validated experimentally for water mist cooling of methane fires in open space [13], and water mist suppression of propane fires in enclosures [14].

In the experiments conducted as described in Refs. [13] and [14], the methane and propane flow rates to the burners were regulated according to the scaling requirement, and maintained constant during each experiment. However, for condensed fuels, the fuel vapor generation is governed by fuel properties, fuel arrangement and fire environment condition, and the latter in turn is influenced by the water mist application and the fire itself. So, before the scaling scheme can be applied to practical water-mist-fire-protection applications, it is imperative to ensure that the fire development of condensed fuels under water mist application can be adequately reproduced in different scales.

This paper presents an evaluation of the applicability of Froude modeling to the scaling of water mist suppression of heptane pool fires in enclosures. The scaling relationships are first briefly reviewed, followed sequentially by the description of experimental facilities, fire source determination, experimental conditions, results and discussion, and conclusions.

\section{FROUDE-MODELING-BASED SCALING RELATIONSHIPS}

The Reynolds number of a droplet motion is defined below:

$$
\operatorname{Re}_{d}=\frac{d\left|\vec{u}_{d}-\vec{u}_{g}\right|}{v_{g}},
$$

where $d$ and $\vec{u}_{d}$ are the droplet diameter and droplet velocity vector, and $\vec{u}_{g}$ and $v_{\mathrm{g}}$ are the gas velocity vector and gas kinematic viscosity, respectively. In the metric system, the diameter, velocity and kinematic viscosity are in the units of meter, meter per second and $\mathrm{m}^{2} / \mathrm{s}$, respectively.

The derivation of the general scaling relationships based on Froude modeling has been described in great detail in Ref. [12]. Table 1 below summarizes the general scaling relationships for spray-plume interactions occurring in any droplet Reynolds number regimes, and the relationships specific for $\mathrm{Re}_{\mathrm{d}} \leq 1$ of our current interest, and $10<\mathrm{Re}_{\mathrm{d}} \leq 500$ for typical sprinkler sprays. In Table $1, \mathrm{~S}$ denotes the scale ratio. The expressions shown in the second and third columns can be obtained respectively by substituting 1 and $1 / 2$ for the power index $x$ shown in the fourth column of Table 1. As shown, all of the key scaling relationships are identical for different regimes of the droplet Reynolds number, except for droplet size and droplet number density.

The experiments described below for water mist suppression of heptane pool fires in enclosures were conducted under the condition of $\operatorname{Re}_{\mathrm{d}} \leq 1$.

\section{FIRE SUPPRESSION EXPERIMENTS}

Two geometrically similar enclosures with a 1:3 scale ratio were constructed for the fire suppression experiments. The parameters considered in the experiments were: enclosure size, door opening size, water mist spray characteristics, fire size, fire location and fire-shielding condition. To continuously measure the fire heat release rate, experiments were conducted using a $200 \mathrm{~kW}$ and a $1 \mathrm{MW}$ capacity fire products collector (FPC) in the Calorimetry Laboratory at the FM Global Research Campus, located in West Glocester, Rhode Island.

\section{Test Enclosures}

The two test enclosures described in Ref. [14] were used for the present experiments, which had a scale ratio of 1:3. Refer to Ref. [14] for a more detailed description of these two enclosures. 
Table 1. Scaling relationships.

\begin{tabular}{|c|c|c|c|}
\hline Scaling parameters & $\mathrm{Re}_{\mathrm{d}} \leq 1$ & $10<\mathrm{Re}_{\mathrm{d}} \leq \mathbf{5 0 0}$ & Any $R_{e}$ Range \\
\hline Droplet drag coefficient & $\propto \operatorname{Re}_{\mathrm{d}}^{-1}$ & $\propto \operatorname{Re}_{\mathrm{d}}^{-1 / 2}$ & $\propto \operatorname{Re}_{\mathrm{d}}^{-x}$ \\
\hline Dimension & $S^{1}$ & $S^{1}$ & $S^{1}$ \\
\hline Time & $S^{1 / 2}$ & $S^{1 / 2}$ & $S^{1 / 2}$ \\
\hline $\begin{array}{c}\text { All scalar parameters } \\
\text { except droplet number density }\end{array}$ & $S^{0}$ & $\mathrm{~S}^{0}$ & $S^{0}$ \\
\hline Droplet number density & $\mathrm{S}^{-3 / 4}$ & $\mathrm{~S}^{-3 / 2}$ & $S^{(3 x-6) /(2 x+2)}$ \\
\hline Velocity & $S^{1 / 2}$ & $S^{1 / 2}$ & $S^{1 / 2}$ \\
\hline Ventilation rate & $S^{5 / 2}$ & $S^{5 / 2}$ & $S^{5 / 2}$ \\
\hline Fire convective heat release rate & $S^{5 / 2}$ & $S^{5 / 2}$ & $S^{5 / 2}$ \\
\hline Total water discharge rate & $S^{5 / 2}$ & $S^{5 / 2}$ & $S^{5 / 2}$ \\
\hline Water flux & $\mathrm{S}^{1 / 2}$ & $S^{1 / 2}$ & $\mathrm{~S}^{1 / 2}$ \\
\hline Total cooling rate & $S^{5 / 2}$ & $S^{5 / 2}$ & $S^{5 / 2}$ \\
\hline Droplet size & $S^{1 / 4}$ & $S^{1 / 2}$ & $S^{(2-x) /(2+2}$ \\
\hline
\end{tabular}

The Scale-1 and Scale-3 enclosures measured $1.22 \times 1.22 \times 1.22 \mathrm{~m}$ and $3.66 \times 3.66 \times 3.66 \mathrm{~m}$, respectively. Both enclosures were of a steel-framed structure, and respectively lined with $1.2-\mathrm{mm}$ and $3.4 \mathrm{~mm}$ thick steel sheet. Both enclosures were completely insulated with $51 \mathrm{~mm}$ thick, aluminum-foil-faced insulation boards with a density of $96.2 \mathrm{~kg} / \mathrm{m}^{3}$ and a thermal conductivity of $0.018 \mathrm{~W} / \mathrm{m} / \mathrm{K}$. Drainage traps were provided below each enclosure to prevent flooding on the enclosure floor.

To evaluate the effect of natural ventilation on fire suppression under water mist application, experiments were conducted with two door opening sizes for each enclosure. For the Scale-1 enclosure, the door opening measured $0.30 \times 0.61 \mathrm{~m}$ high or $0.61 \times 0.61 \mathrm{~m}$; for the Scale- 3 enclosure, the door opening was $0.91 \times 1.83 \mathrm{~m}$ high or $1.83 \times 1.83 \mathrm{~m}$.

Figures 1 and 2 show the Scale- 1 and Scale- 3 enclosures, and the gas collection hood of each FPC above the enclosure door opening.

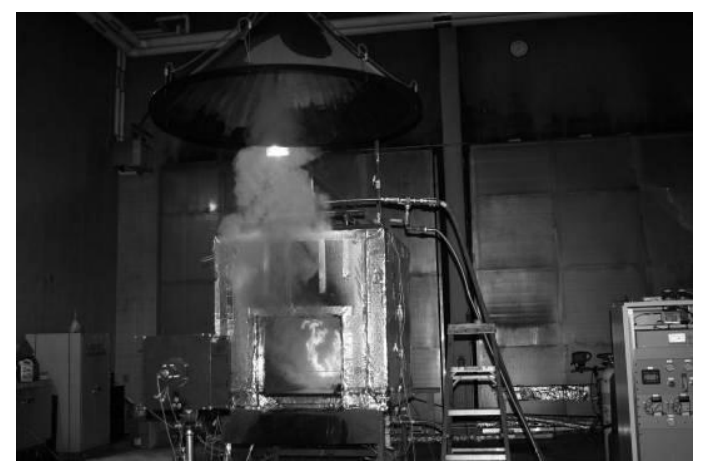

(a)

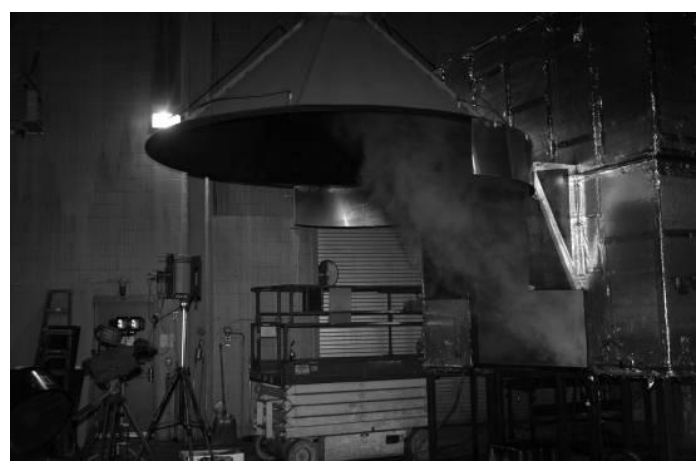

(b)

Fig. 1. Photographic illustrations: (a) the Scale-1 enclosure and the 200 kW FPC; (b) the Scale- 3 enclosure and the $1 \mathrm{MW}$ FPC.

\section{Enclosure Instrumentation}

Each enclosure was instrumented to measure the radiant heat flux from the door opening, heat flux into the enclosure surface, enclosure surface temperature, thermal stratification in the enclosure, and gas concentrations in the enclosure. Only the gas concentration measurement is described in this paper.

Continuous gas sampling was performed to monitor the gas concentrations inside the enclosure using Rosemount Analytical Type MLT multi-gas analyzers. 
For the Scale-1 enclosure, the floor-level concentrations of $\mathrm{O}_{2}, \mathrm{CO}_{2}, \mathrm{CO}$ and THC were measured near the far left corner of the enclosure from the door opening, and only the floor-level $\mathrm{O}_{2}$ concentration was measured near the far right corner. At each corner, a $6.4 \mathrm{~mm}$ OD (4.6 mm ID) stainless steel tube was inserted through the back wall, $10 \mathrm{~cm}$ above the enclosure floor and $10 \mathrm{~cm}$ near the adjacent wall. The tube was extended into the enclosure for about $25 \mathrm{~mm}$ to avoid drawing the water falling down along the back wall.

For the Scale-3 enclosure, gas concentrations were also measured near the far left and far right corners from the door opening. The floor-level gas sampling arrangement near the far right corner was similar to that for the Scale-1 enclosure, except that the stainless steel tube was positioned $31 \mathrm{~cm}$ above the enclosure floor and $31 \mathrm{~cm}$ from the right wall relative to the door opening. Only the floor-level $\mathrm{O}_{2}$ concentration was measured at this location. Near the far left corner, the gas sampling arrangement consisted of five $6.4 \mathrm{~mm}$ OD (4.6 mm ID) stainless steel tubes positioned at $0.61,1.22,1.83,2.44$ and $3.05 \mathrm{~m}$ above the enclosure floor, all with a $25 \mathrm{~mm}$ standoff distance from the back wall and $31 \mathrm{~cm}$ from the left wall. Outside the enclosure, these tubes were connected to a $15.9 \mathrm{~mm}$ OD (12.5 mm ID) vertical manifold. At this corner, the bulk concentrations of $\mathrm{O}_{2}$, $\mathrm{CO}_{2}, \mathrm{CO}$ and THC were measured.

In the Scale-1 and Scale-3 experiments, the gases withdrawn from the enclosure's left and right corners were fed independently to two separate racks of gas analyzers. The particulates and water vapor in each gas sampling stream were removed by a micro-filter and desiccator cylinder loosely packed with Drierite.

\section{Fire Products Collectors}

Figure 1 shows the $200 \mathrm{~kW}$ and $1 \mathrm{MW}$ FPCs positioned above the Scale-1 and Scale- 3 enclosure door openings collecting the gas effluent. The following measurements were made continuously in both the $200 \mathrm{~kW}$ and 1 MW FPCs: duct surface temperature, duct gas temperature, exhaust rate in the duct, and concentrations of $\mathrm{CO}_{2}, \mathrm{CO}, \mathrm{O}_{2}$, total hydrocarbon and water vapor in the exhaust stream, and ambient temperature. The temperatures were measured with 30-gage K-type thermocouples. The gas concentrations were measured with Rosemount analyzers except for water vapor concentrations, which were measured with a Vaisala HMP235 sensor. The gas sampling line from the duct to the gas analyzers was heat traced to prevent condensation. Except for water vapor, concentration measurements were corrected for time lag due to the gas transport time in the sampling line and the sensing delays of the individual analyzers [15]. Based on the gas exhaust rate, gas concentrations and temperature in the FPC, FPC duct temperature and ambient conditions, the fire heat release rate and convective heat flow rate carried in the gas effluent could be determined.

The fire heat release rate was calculated from the dry-based concentrations of $\mathrm{CO}_{2}$ and $\mathrm{CO}$ and dry-based gas mass flow rate in the FPC [16]. The dry-based mass flow rate was obtained by subtracting the water vapor mass flow rate from the measured mass flow rate in the FPC. In calculating the fire heat release rate, the heat generation per unit mass production of $\mathrm{CO}_{2}$ and $\mathrm{CO}$ was taken to be $14.5 \mathrm{~kJ} / \mathrm{g}$ and $12.8 \mathrm{~kJ} / \mathrm{g}$ for heptane fires [16].

\section{Water Mist Sprays and Nozzle Layout}

The Hago 2.25-60P and Hago 20-60P nozzles used in the previous study of water mist suppression of propane fires [14] were employed in the present experiments to produce the water mist sprays in the Scale-1 and Scale3 enclosures. These two nozzles generated solid-cone sprays. The key spray properties of these two nozzles at the designated Scale-1 and Scale-3 operating pressures of 13.8 bar and 41.4 bar are presented in Table 2.

In Table 2, $d_{v 0.5}$ denotes the volume-median droplet diameter of the spray. Figure 2 shows the cumulative volume fraction versus droplet size normalized with $d_{v 0.5}$ for these two nozzles, which indicates that the gross droplet size distributions of these two sprays are similar. The values of $d_{v 0.5}$ and discharge rate per nozzle given in the parentheses in the table are the ideal values based on the scaling relationships presented in Table 1 for $\mathrm{Re}_{\mathrm{d}} \leq 1$. The impact of the slightly larger Scale-3 droplet than the ideal value on the fire suppression results will be discussed later. 
Table 2. Water mist spray properties.

\begin{tabular}{|c|c|c|c|c|c|}
\hline Scale & Nozzle & $\begin{array}{c}\text { Pressure } \\
(\mathbf{b a r})\end{array}$ & $\begin{array}{c}\text { Spray } \\
\text { angle (degree) }\end{array}$ & $\begin{array}{c}\boldsymbol{d}_{\boldsymbol{v} 0.5} \\
(\boldsymbol{\mu} \mathbf{m})\end{array}$ & $\begin{array}{c}\text { Discharge rate } \\
\text { per nozzle }(\mathbf{L} / \mathbf{m i n})\end{array}$ \\
\hline 1 & Hago 2.25-60P & 13.8 & 60 & 62 & 0.183 \\
\hline 3 & Hago 20-60P & 41.4 & 60 & 90 & 2.782 \\
$(82)^{*}$ & $(2.853)^{*}$ \\
\hline
\end{tabular}

Note: The values in the parentheses are the ideal values based on the scaling relationships for $\operatorname{Re}_{\mathrm{d}} \leq 1$ presented in Table 1.

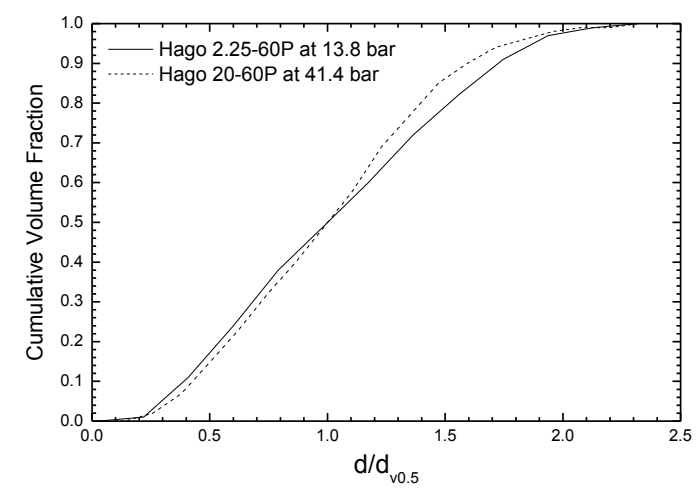

Fig. 2. The gross droplet size distributions of the Hago 2.25-60P and Hago 20-60P nozzles.

In each enclosure, nine nozzles were arranged in a $3 \times 3$ matrix with equal spacing between adjacent nozzles and between nozzles and adjacent walls. Using $25 \mathrm{~mm}$ SS316 tubing and fittings, the water was supplied to the nozzles from above the enclosure ceiling through drop tubes. These drop tubes were connected to three branch lines, three on each line. The branch lines were in turn connected on-end to a manifold. The nozzles were secured underneath the enclosure ceiling using threaded fittings, resulting in nozzle tips being about $32 \mathrm{~mm}$ below the ceiling.

A high pressure pump rated $114 \mathrm{~L} / \mathrm{min}$ at 69 bar was used to supply the required water discharge rates. A $100 \mu \mathrm{m}$ filter was installed at the pump intake and a $20 \mu \mathrm{m}$ filter was installed at the inlet of the enclosure piping system to remove particulates. The water supply line consisted of one shut-off valve upstream and one shut-off valve downstream of the manifold, and two water by-passes: one at the pump and the other downstream of the $20 \mu \mathrm{m}$ filter. The nozzle discharge pressure was monitored with a 69 bar rated pressure transducer (Trans-Metrics Model P21EA-10) at the junction of the manifold and the middle branch line above the enclosure. The water temperature inside the drop tube was monitored at two locations using grounded Type-K thermocouples: one at the ceiling center and the other near the right corner of the wall containing the door opening.

\section{Heptane Pool Fires}

Based on the previous experiments conducted with the propane fires [14], it was decided that a fire size with a maximum heat release rate of $20-25 \mathrm{~kW}$ be used for the Scale-1 experiments, so the fire would be small enough to be sustained (i.e., not be extinguished by the water mist) but large enough for measurements with the $200 \mathrm{~kW}$ FPC. To obtain fire extinguishment results, a larger pool fire was selected with the maximum heat release rate in the range of $45-55 \mathrm{~kW}$. For the Scale-3 experiments, the corresponding ranges of the maximum fire heat release rates for the smaller and larger fires were thus $300-390 \mathrm{~kW}$ and $700-860 \mathrm{~kW}$, respectively, based on the scaling requirement. The determination of the pool diameters to provide the above targeted heat release rates is described below.

The quasi-steady heat release rates of heptane pool fires with diameters of $0.38,0.61$, and $1.09 \mathrm{~m}$ were first measured to be 125, 465 and $2230 \mathrm{~kW}$, respectively. Based on these measurements and other heptane pool fire 
data for diameters up to $2 \mathrm{~m}$ [17], the heat release rates of heptane pool fires can be expressed as a function of pool diameter [18]:

$$
\dot{q}_{\text {pool }}^{\prime \prime}=3116\left(1-e^{-1.3 D}\right),
$$

where $\dot{q}_{\text {pool }}$ is the heat release rate per unit pool area in $\mathrm{kW} / \mathrm{m}^{2}$, and $D$ is the pool diameter in meters.

Using Eq. 2 as a guide, candidate Scale-1 and Scale-3 pool diameters were selected for the above targeted heat release rates. After measuring the heat release rates using the FPCs, the pool diameters for the Scale-1 experiments were determined to be 0.23 and $0.32 \mathrm{~m}$, and 0.55 and $0.74 \mathrm{~m}$ for the Scale- 3 experiments. Each of the Scale-1 and Scale-3 pools consisted of about $25 \mathrm{~mm}$ deep heptane floating on a layer of $25 \mathrm{~mm}$ deep water in a $102 \mathrm{~mm}$ deep steel pan. According to Eq. 2, for $\dot{q}_{\text {pool }}$ to reach above $90 \%$ of the asymptotic value of $3116 \mathrm{~kW} / \mathrm{m}^{2}$, the pool diameter should be at least $1.8 \mathrm{~m}$. Since all the selected Scale- 1 and Scale- 3 pool diameters were less than $1.8 \mathrm{~m}$, each of the Scale-3 pool fires was expected to be more radiative than the corresponding Scale-1 pool fire.

The above selected pool diameters for the corresponding Scale-1 and Scale-3 experiments do not conform strictly with the linear-scaling requirement for pool diameter. However, it has been shown that for flameheight-versus-pool-diameter ratios ranging from 0.7 to 2.3 , the air entrainment to a turbulent flame depends mainly on its heat release rate. The effect of pool diameter on entrainment was not noticeable under this condition [19]. Since the above height/diameter ratio depends on $\dot{Q}_{C}^{2 / 5} / D$, where $\dot{Q}_{C}$ is the fire convective fire heat release rate, the deviation of the above two Scale-3 pool diameters from the respective ideal diameters of $0.69 \mathrm{~m}$ and $0.96 \mathrm{~m}$ was deemed negligible for the effect on air entrainment as long as the heat release rate was properly scaled.

Figure 3 presents the histories of fire heat release rate for the free-burning Scale-1 $0.23 \mathrm{~m}$ and $0.32 \mathrm{~m}$ diameter pools, and the histories for the Scale- $30.55 \mathrm{~m}$ and $0.74 \mathrm{~m}$ diameter pools. As shown, the reproducibility of the fire development was reasonably good, and the variation of quasi-steady heat release rates shortly after ignition was within $5 \%$ for these pool fires. The quasi-steady heat release rates of the $0.23,0.32,0.55$ and $0.74 \mathrm{~m}$ heptane pool fires were about $25,57,380$ and $860 \mathrm{~kW}$, respectively.

The heat release rate measurement uncertainty was evaluated by comparing the heat generation per gram of burned heptane to the commonly recognized value of $41.2 \mathrm{~kJ} / \mathrm{g}$ for heptane pool fires under well-ventilated conditions [16]. Based on the heat release rate and heptane weight-loss measurements, the heat generation of heptane ranged from 38.0 to $43.8 \mathrm{~kJ} / \mathrm{g}$ for the measurements shown in Figs. 3 and 4, which were $-7.8 \%$ to $+6.3 \%$ relative to the value of $41.2 \mathrm{~kJ} / \mathrm{g}$. With the $6.5 \%$ uncertainty for the FPC heat-release-rate measurement and $2 \%$ uncertainty for the weight-loss measurement based on the load-cell calibration, the combined uncertainty for the calculated heat release per gram thus ranged from $-8.4 \%$ to $+8.6 \%$, which was consistent with the above variation with respect to the commonly recognized value.

Figure 4 compares the histories of heat release rate for the corresponding smaller and larger pool fires used in the Scale-1 and Scale-3 experiments. The comparisons are made on the Scale-3 coordinates for both the time and fire heat release rate. For clarity, only one measurement for each scale is presented in the comparisons. As shown, the Scale-1 and Scale-3 fire developments were reproduced quite well before heptane was consumed in the Scale-3 measurements. As mentioned above, all the Scale-1 and Scale-3 pool fires had the same starting heptane depth of $25 \mathrm{~mm}$. Since each of the Scale-3 fires was more radiative than its corresponding Scale-1 fire, the fuel was consumed faster by the Scale-3 fire. It was judged that the quasi-steady burn time afforded by the $25 \mathrm{~mm}$ heptane layer was sufficiently long for the Scale-3 experiments with water mist application. Therefore, no attempt was made to increase the Scale-3 fire durations to those of the Scale-1 fires by increasing the heptane layer depth in the Scale-3 pools. 


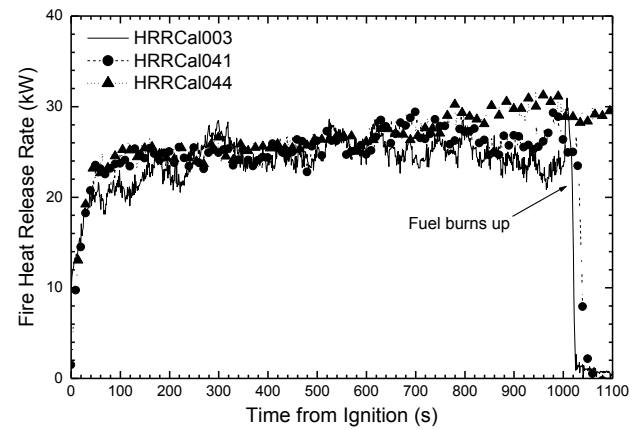

(a)

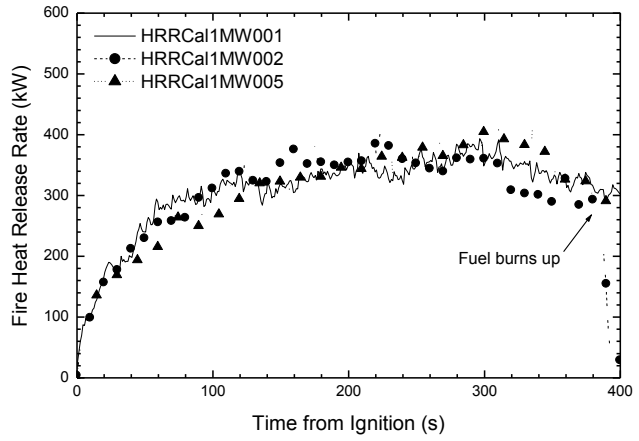

(c)

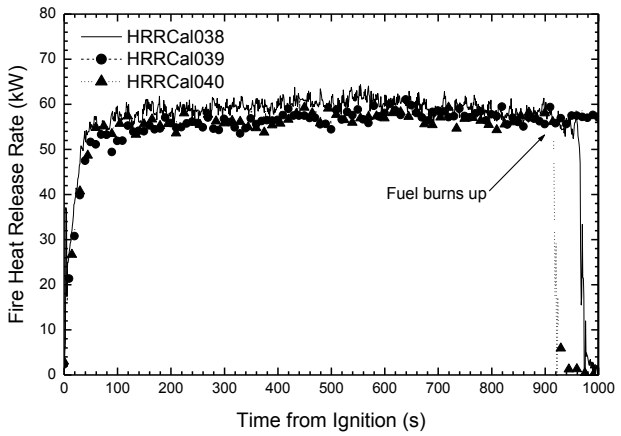

(b)

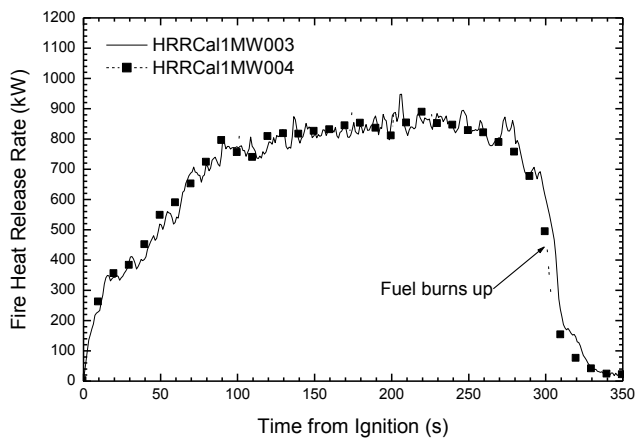

(d)

Fig. 3. The fire heat release rate histories. (a) Scale-1 $0.23 \mathrm{~m}$ pool; (b) Scale-1 $0.32 \mathrm{~m}$ pool; (c) Scale-3 $0.55 \mathrm{~m}$ pool; (d) Scale-3 $0.74 \mathrm{~m}$ pool.

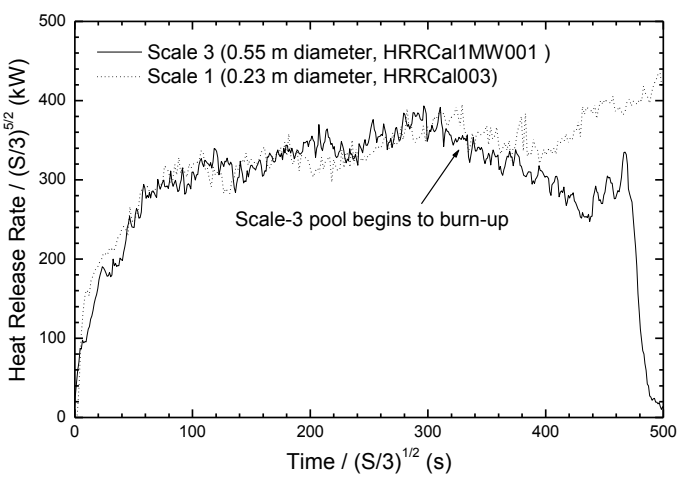

(a)

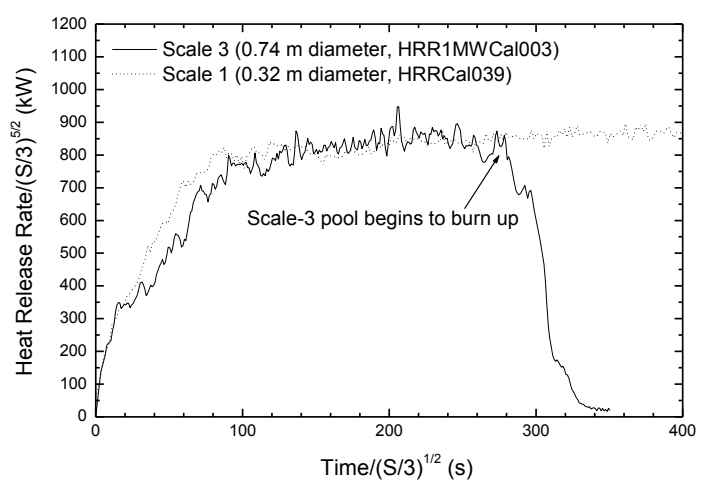

(b)

Fig. 4. Comparisons of the Scale-1 and Scale-3 heptane pool fire developments for the corresponding: (a) smaller fires; (b) larger fires.

\section{Fire Locations}

To investigate the effect of fire location on the fire suppression result, the heptane pool fire was either located at the center of the enclosure floor or moved away from the door opening toward the back wall by half the nozzle spacing. 


\section{Fire Shields and Shield Orientations}

Except for a few experiments, to minimize the direct interaction between the water mist sprays and fire, the fire was protected with a metal shield consisting of a horizontal top cover welded to two opposite walls. The shield was fabricated with the same sheet metal used to construct the Scale-1 and Scale- 3 enclosures. For the Scale-1 experiments, the shield's top cover measured $0.41 \times 0.41 \mathrm{~m}$, and the two side walls each measured $0.41 \times 0.61 \mathrm{~m}$ high. For the Scale-3 experiments, the shield's top cover and its two side walls measured $1.22 \times 1.22 \mathrm{~m}$ and $1.22 \times 1.83 \mathrm{~m}$ high, respectively.

To evaluate the impact of air flow pattern from the door opening to the fire, two shield orientations were tested in the experiments. The first orientation was to align the two shield openings to the door opening; the second orientation was to rotate the shield by $90^{\circ}$ so that the two opposite walls of the shield were aligned to the door opening.

\section{EXPERIMENTAL PARAMETERS}

Based on the above descriptions, the key experimental parameters are summarized in Table 3. For the corresponding Scale-1 and Scale-3 experiments, the water mist application was started at the corresponding fire heat release rates (i.e., $S^{2.5}$ ), instead of at the corresponding time lapse $\left(S^{1 / 2}\right)$ after ignition, considering the fact that the time for the initial fire development could vary. The designated fire heat release rates at water mist application were $22 \mathrm{~kW}$ and $55 \mathrm{~kW}$ for the Scale-1 experiments, and 340 and $860 \mathrm{~kW}$ for the Scale-3 experiments.

Table 3. Key experimental parameters.

\begin{tabular}{|c|c|c|c|c|c|c|}
\hline Scale & $\begin{array}{c}\text { Enclosure size } \\
(\text { width } \times \text { depth } \times \\
\mathbf{h e i g h t )} \\
(\mathbf{m} \times \mathbf{m} \times \mathbf{m})\end{array}$ & $\begin{array}{c}\text { Door opening } \\
\text { size } \\
(\mathbf{w i d t h} \times \\
\mathbf{h e i g h t}) \\
(\mathbf{m} \times \mathbf{m})\end{array}$ & $\begin{array}{c}\text { Nominal quasi- } \\
\text { steady free- } \\
\text { burn heat } \\
\text { release rate } \\
(\mathbf{k W})\end{array}$ & $\begin{array}{c}\text { Discharge } \\
\text { pressure }\end{array}$ & $\begin{array}{c}\text { Drop } \\
\text { size }\end{array}$ & $\begin{array}{c}\text { Total water } \\
\text { mist } \\
\text { discharge } \\
\text { rate } \\
(\mathbf{L} / \mathbf{m i n})\end{array}$ \\
\hline 1 & $1.22 \times 1.22 \times 1.22$ & $\begin{array}{c}0.30 \times 0.61 \\
0.61 \times 0.61\end{array}$ & 25,57 & 13.8 & 62 & 1.65 \\
\hline 3 & $3.66 \times 3.66 \times 3.66$ & $\begin{array}{c}0.91 \times 1.83 \\
1.83 \times 1.83\end{array}$ & 380,860 & 41.4 & 90 & 25.0 \\
\hline
\end{tabular}

\section{RESULTS AND DISCUSSIONS}

Table 4 lists the 16 scenarios for the corresponding Scale-1 and Scale-3 experiments. In Scenarios 13-16, the fire shield was removed from the enclosure so that the pool fire was directly exposed to the water mist sprays. For the majority of the test scenarios, at least two tests were conducted for each scale.

\section{Fire Development}

Figures 5 and 6 present the comparisons of the fire heat release rates measured in the corresponding Scale-1 and Scale-3 experiments for all the test scenarios listed in Table 4. The comparisons are made on the same (Scale-1) basis, i.e. time is normalized by $S^{1 / 2}$ and the heat release rate is normalized by $S^{5 / 2}$. The individual tests' results are presented in these figures except for Scenario 1, where four Scale-1 tests were conducted and five Scale-3 tests were conducted. To avoid cluttering the figure, the composite results for Scenario 1 are presented, where the Scale-1 and Scale-3 heat release rates at each instant are the averages of all the conducted tests. The horizontal bars for each curve indicate the ranges in which the heat release rates varied in the replicated tests.

Overall, the developments of the Scale-1 pool fires were reproduced reasonably well in the Scale-3 experiments, and vice versa. As shown in Figs. 5 and 6, the Scale-3 fire tended to be suppressed relatively faster than the corresponding Scale-1 fire when compared on the same time scale basis. This could be due to the fact that the Scale-3 fires were more radiative than the corresponding Scale-1 fires, and the droplets of the 
Table 4. Test scenarios.

\begin{tabular}{|c|c|c|c|c|c|c|c|c|}
\hline \multirow{2}{*}{ Scenario } & \multirow{2}{*}{$\begin{array}{c}\text { Pool } \\
\text { location } \\
\text { on floor }\end{array}$} & \multicolumn{2}{|c|}{$\begin{array}{c}\text { Pool diameter } \\
(\mathbf{m})\end{array}$} & \multicolumn{2}{c|}{$\begin{array}{c}\text { Discharge } \\
\text { pressure } \\
\text { (bar) }\end{array}$} & \multicolumn{2}{c|}{$\begin{array}{c}\text { Door opening } \\
\text { size }\end{array}$} & $\begin{array}{c}\text { Shield } \\
\text { openings } \\
\text { facing door } \\
\text { opening? }\end{array}$ \\
\cline { 3 - 8 } & Scale 1 & Scale 3 & Scale 1 & Scale 3 & Scale 1 & Scale 3 & Yes \\
\hline 1 & Center & 0.23 & 0.55 & 13.8 & 41.4 & Smaller & Smaller & Yes \\
\hline 2 & Center & 0.32 & 0.74 & 13.8 & 41.4 & Smaller & Smaller & No \\
\hline 3 & Center & 0.23 & 0.55 & 13.8 & 41.4 & Smaller & Smaller & No \\
\hline 4 & Center & 0.32 & 0.74 & 13.8 & 41.4 & Smaller & Smaller & Yes \\
\hline 5 & Offset & 0.23 & 0.55 & 13.8 & 41.4 & Smaller & Smaller & Yes \\
\hline 6 & Offset & 0.32 & 0.74 & 13.8 & 41.4 & Smaller & Smaller & Yo \\
\hline 7 & Offset & 0.23 & 0.55 & 13.8 & 41.4 & Smaller & Smaller & No \\
\hline 8 & Offset & 0.32 & 0.74 & 13.8 & 41.4 & Smaller & Smaller & No \\
\hline 9 & Offset & 0.23 & 0.55 & 13.8 & 41.4 & Larger & Larger & Yes \\
\hline 10 & Offset & 0.23 & 0.55 & 13.8 & 41.4 & Larger & Larger & No \\
\hline 11 & Center & 0.23 & 0.55 & 13.8 & 41.4 & Larger & Larger & Yes \\
\hline 12 & Center & 0.23 & 0.55 & 13.8 & 41.4 & Larger & Larger & No \\
\hline 13 & Center & 0.23 & 0.55 & 13.8 & 41.4 & Smaller & Smaller & No Shield \\
\hline 14 & Center & 0.23 & 0.55 & 13.8 & 41.4 & Larger & Larger & No Shield \\
\hline 15 & Center & 0.32 & 0.74 & 13.8 & 41.4 & Larger & Larger & No Shield \\
\hline 16 & Center & 0.32 & 0.74 & 13.8 & 41.4 & Smaller & Smaller & No Shield \\
\hline
\end{tabular}

Scale-3 spray was larger than the ideal value per the scaling requirement. The more radiative fire in the Scale-3 experiments resulted in a relatively hotter enclosure environment at the start of water mist application, therefore tended to produce a higher droplet vaporization rate than the ideal rate at the start. Furthermore, since the droplets of the Scale-3 spray were larger than the ideal value, the spray tended to transfer their momentum to the enclosure gas in a longer spray distance. Therefore, the spray-induced gas flow tended to have a greater impact on diluting the fuel vapor near the pool surface. To resolve the above speculations, additional investigation is required.

Both the Scale-1 and Scale-3 fires were extinguished in the corresponding tests except for Scenarios 9, 11 and 12 , where the tests of each scale were conducted with the smaller fire and the larger door opening. For these three scenarios, both the Scale-1 and Scale-3 fires persisted steadily under water mist application until the heptane was consumed. As mentioned above, heptane was consumed faster in the Scale-3 experiments.

In general, the fire was suppressed more quickly at the offset location as the other conditions were kept the same in each scale. However, the relative impact of fire location on suppression effectiveness was also affected by the fire shield orientation and fire size. For instance, when the shield openings faced the door opening, i.e. comparing Scenarios 1 and 5, and Scenarios 2 and 6, the impact of fire location on suppression was less pronounced for both the smaller and larger Scale-3 fires, while was significant for the larger Scale-1 fire. When the shield openings did not face the door opening, i.e. comparing Scenarios 3 and 7, and Scenarios 4 and 8, the fire-location impact for the smaller Scale-3 fire was larger than the impact for the larger Scale-3 fire, but significant for both the smaller and larger Scale-1 fires.

When the pool fire was directly exposed to the water mist sprays, the fire was quickly suppressed and extinguished in the Scale-1 and Scale-3 experiments after water mist application as shown in Fig. 6 for Scenarios 13-16.

\section{Enclosure Floor-Level Oxygen Concentrations}

As indicated in Table 1, the scalar parameters in Froude modeling are supposed to be reproduced in different scales, which include the gas concentrations inside the enclosure. As mentioned above, the floor-level oxygen concentration was measured in the Scale-1 enclosure near the far left and far right corners from the door 

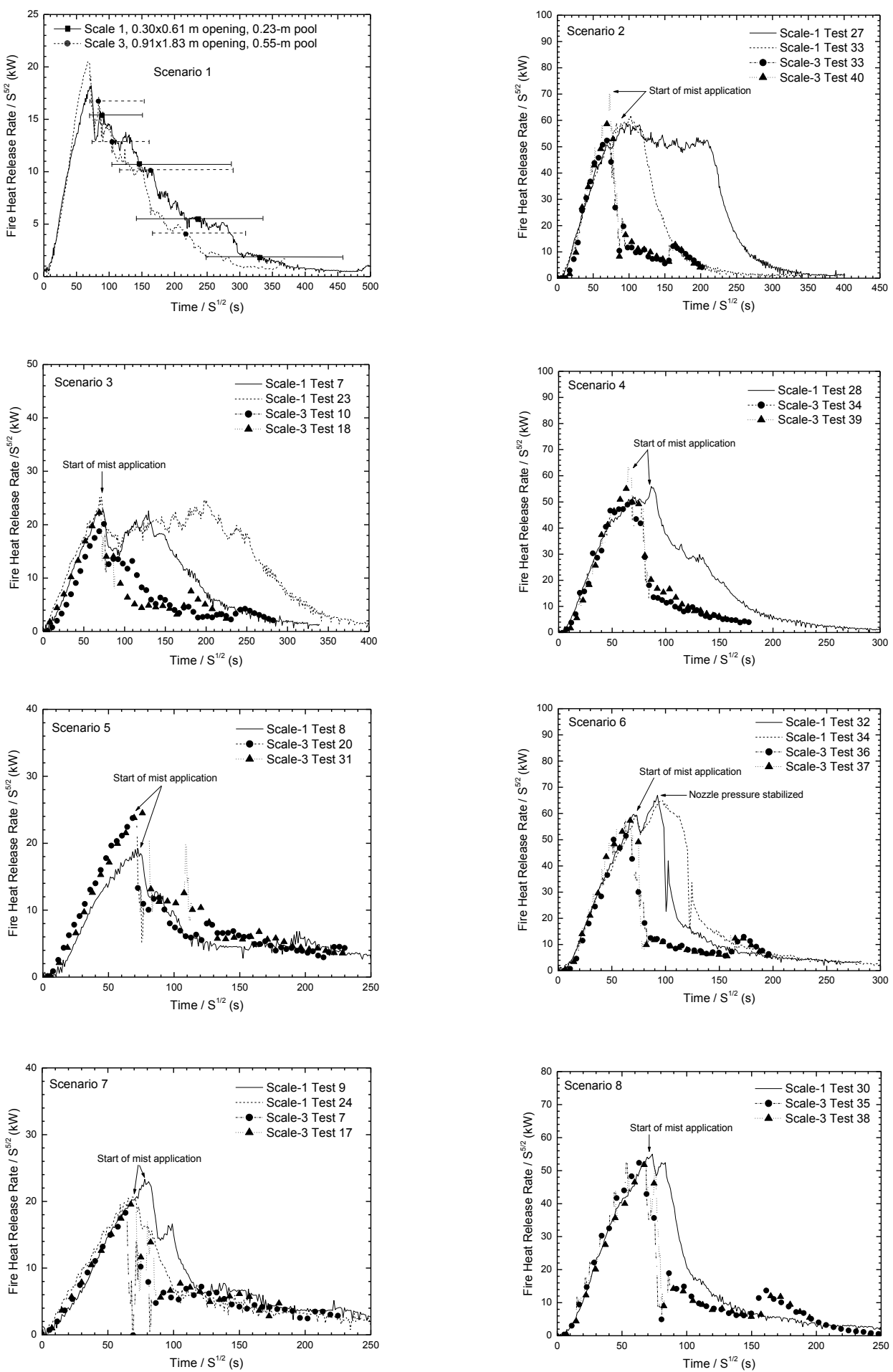

Fig. 5. Comparisons of Scale-1 and Scale-3 fire development for Scenarios 1-8. 

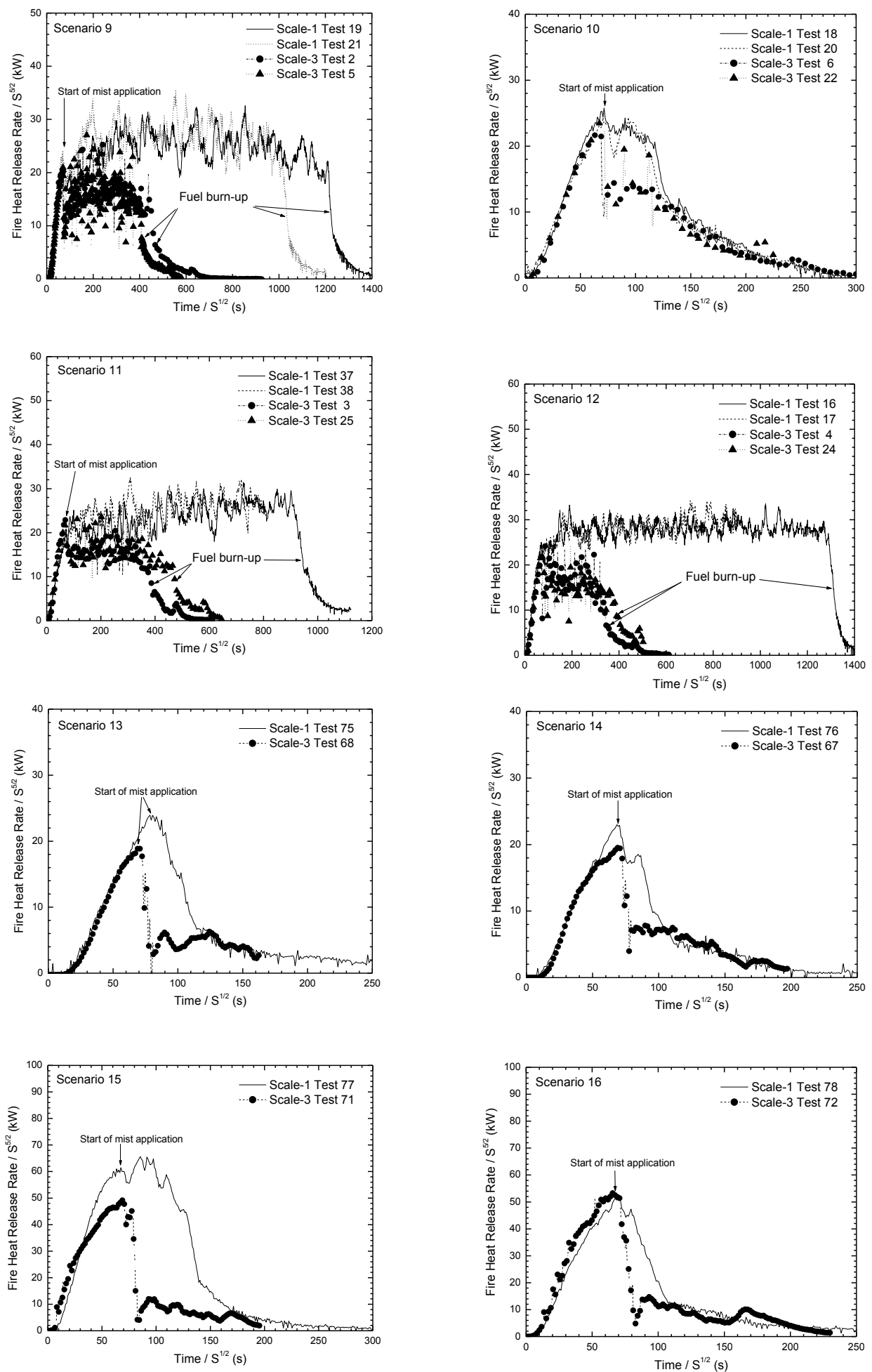

Fig. 6. Comparisons of Scale-1 and Scale-3 fire development for Scenarios 9-16. 

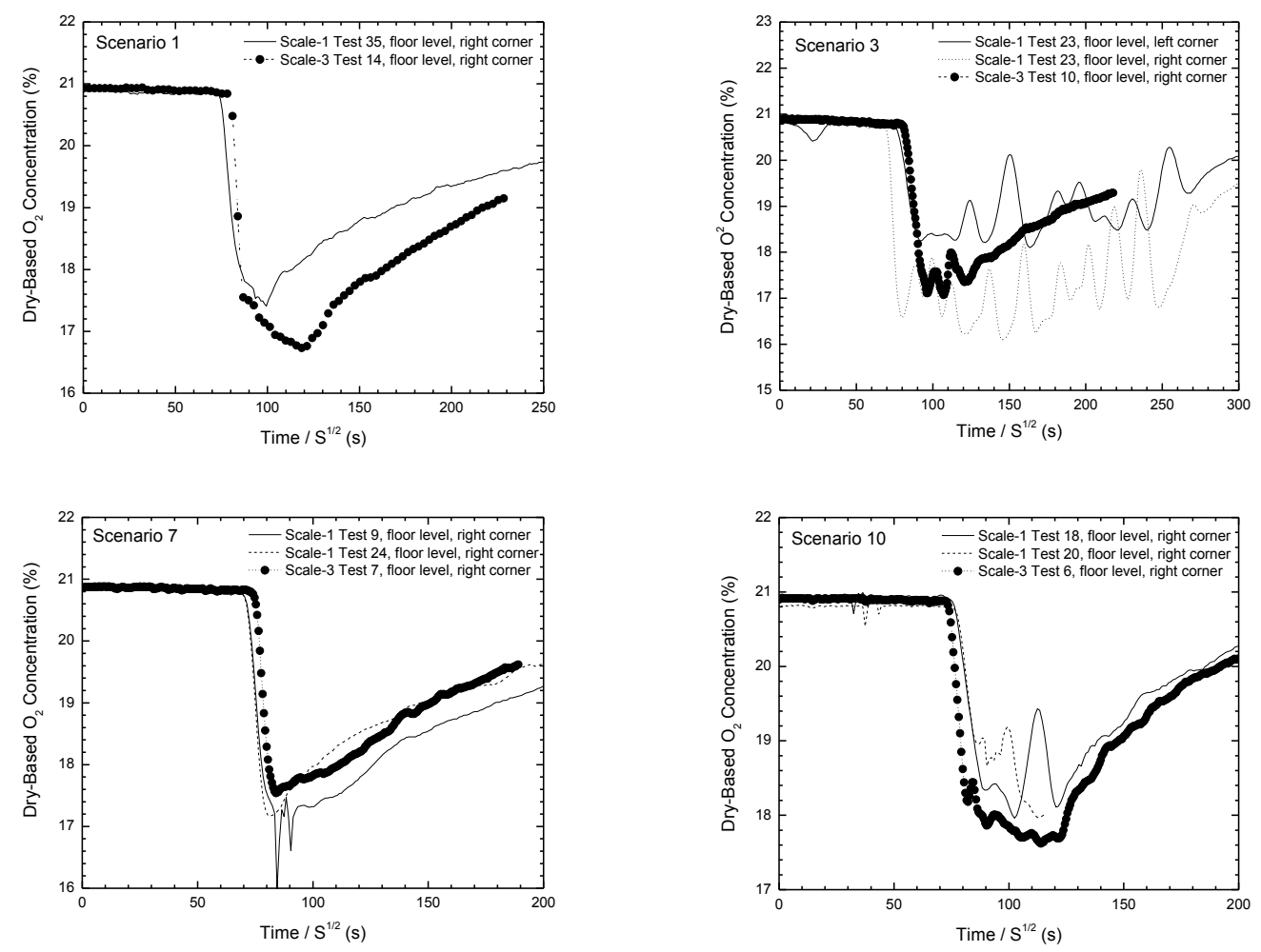

Fig. 7. Floor-level oxygen concentrations measured in the Scale-1 and Scale-3 experiments for Scenarios 1, 3, 7 and 10 .
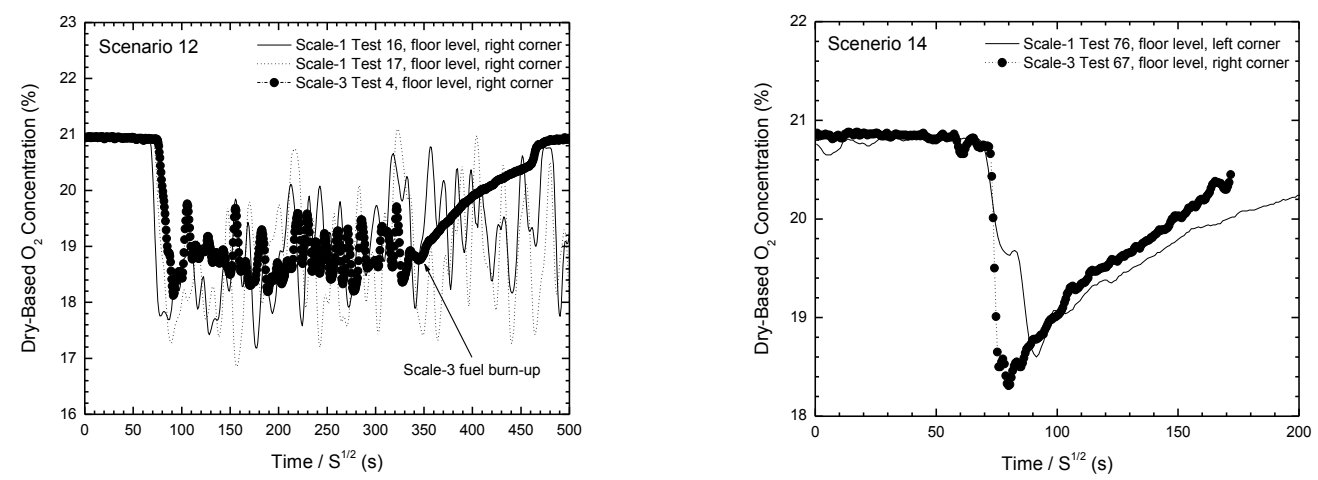

Fig. 8. Floor-level oxygen concentrations measured in the Scale-1 and Scale-3 experiments for Scenarios 12 and 14.

opening, while near the far left corner in the Scale-3 enclosure. Figures 7 and 8 present the dry-based floorlevel oxygen concentrations for six representative scenarios. As shown, the agreement was reasonably good between the corresponding experiments at the two scales.

\section{CONCLUSIONS}

A series of fire suppression experiments was conducted in two geometrically similar enclosures of 1:3 ratio to evaluate whether the Froude-modeling-based scaling methodology could reasonably reproduce the pool fire development under water mist application in different scales. Heptane pool fires were used in these experiments. The parameters considered in the evaluation were: enclosure size, door opening size, water mist 
spray condition, fire size, fire location and fire-shielding condition. The experiments showed that the fire development in terms of heat release rate could be reasonably reproduced during free-burn and water mist application in the Scale-1 and Scale-3 enclosures. The instantaneous oxygen concentration inside the enclosure was also reasonably reproduced in the corresponding Scale-1 and Scale-3 experiments, as expected from Froude modeling. Based on the generally positive results obtained from this investigation, it can be concluded that the Froude-modeling-based scaling methodology is applicable to general water mist fire protection problems for flammable liquid fires.

\section{REFERENCES}

[1] Jones, A. and Nolan, P.F., (1995) Discussions on the use of fine water sprays or mists for fire suppression, J. Loss Prevention in the Process Industries 8: 17-22. http://dx.doi.org/10.1016/0950$\underline{4230(95) 90057-\mathrm{V}}$

[2] DesJardin, P.E., Gritzo, L.A. and Tieszen, S.R., "Modeling the Effect of Water Spray Suppression on Large-Scale Pool Fires", Halon Options Technical Working Conference, 2000, pp. 262-273.

[3] Prasad, K., Patnaik, G. and Kailasanath, K., (2002) A numerical study of water-mist suppression of large scale compartment fires, Fire Safety Journal 37: 569-589. http://dx.doi.org/10.1016/S0379$\underline{7112(02) 00004-8}$

[4] Adiga, K.C., Hatcher, R.F. Jr, Sheinson, R.S., Williams, F.W. and Ayers, S., (2007) A computational and experimental study of ultra fine water mist as a total flooding agent, Fire Safety Journal 42: 150-160. http://dx.doi.org/10.1016/j.firesaf.2006.08.010

[5] Zalosh, R.G. and Bajpai, S.N., "The Effect of Water Fogs on the Deliberate Ignition of Hydrogen," Electric Power Research Institute Report NP-2637, Palo Alto, CA, 1981.

[6] Blouquin, R. and Joulin, G., "On the Quenching of Premixed Flames by Water Sprays: Influences of Radiation and Polydispersity", Proceedings of Twenty-Seventh Symposium (International) on Combustion, The Combustion Institute, 1998, pp. 2829-2837. http://dx.doi.org/10.1016/S0082$\underline{0784(98) 80141-0}$

[7] Kung, H.C., Yu, H.Z., Brown, W.R. and Vincent, B.G., 1989. Four-tier Array Rack Storage Fire Tests with Fast-response Prototype Sprinklers. Fire Safety Science 2: 633-642. http://dx.doi.org/10.3801/IAFSS.FSS.2-633

[8] Ishizuka, S. and Tsuji, H., "An Experimental Study of Effect of Inert Gases on Extinction of Laminar Diffusion Flames," Proceedings of Eighteenth Symposium (International) on Combustion, The Combustion Institute, 1981, pp. 695-703. http://dx.doi.org/10.1016/S0082-0784(81)80074-4

[9] Tsuji, H. and Yamaoka, I., "Structure and Extinction of Near-Limit Flames in a Stagnant Flow," Proceedings of Nineteenth Symposium (International) on Combustion, The Combustion Institute, 1982, pp. 1533-1540. http://dx.doi.org/10.1016/S0082-0784(82)80330-5

[10] Mesli, B., Quilgars, A., Chauveau, C. and Gokalp, I., 2000. Extinction Limits of Opposed Jet Turbulent Premixed Methane Air Flames with Water Mist. Fire Safety Science 6: 445-456. http://dx.doi.org/10.3801/IAFSS.FSS.6-445

[11] Heskestad, G., (1975) Physical Modeling of Fire, Fire \& Flammability 6:254-273.

[12] Yu, H-Z, "A Revisit of Froude-Modeling-Based Physical Scaling of Fire Suppression by Water Sprays," Suppression and Detection Research and Applications: A Technical Working Conference (SUPDET 2009), International Plaza Resort \& Spa, Orlando, Florida, February 24-27, 2009.

[13] Jayaweera, T.M. and Yu, H-Z, (2008) Scaling Water Mist Fire Suppression Under Low Drop Reynolds Number Conditions, Fire Safety Journal 43(1): 63-70. http://dx.doi.org/10.1016/j.firesaf.2007.01.004

[14] Yu, H.Z., Zhou, X. and Ditch, B., 2009. Experimental Validation of Froude-modeling-based Physical Scaling of Water Mist Cooling of Enclosure Fires. Fire Safety Science 9: 553-564. http://dx.doi.org/10.3801/IAFSS.FSS.9-553 
[15] Croce P.A., (1976) A method for improved measurement of gas concentration histories in rapidly developing fires, Combustion Science and Technology 14:221-228. http://dx.doi.org/10.1080/00102207608547530

[16] Tewarson A., "Generation of heat and chemical compounds in fires," The SFPE Handbook of Fire Protection Engineering $\left(3^{r d} e d\right.$ ), DiNenno P.J. (ed.), National Fire Protection Association, Quincy, MA 02269, 2002, p. 3/82.

[17] Kung, H.C., and Stavrianidis, P., "Buoyant Plumes of Large-Scale Pool Fires," Proceedings of Nineteenth Symposium (International) on Combustion, The Combustion Institute, 1982, pp. 905912, http://dx.doi.org/10.1016/S0082-0784(82)80266-X

[18] Burgess, D.S., Strasser, A. and Grumer, J., (1961) Diffusive Burning of Liquid Fuels in Open Trays, Fire Research Abstract and Reviews 3(3): 177-192.

[19] Heskestad, G., "Fire Plume Air Entrainment According to Two Competing Assumptions", Proceedings of Twenty-first Symposium (International) on Combustion, The Combustion Institute, 1986, pp. 111-120. http://dx.doi.org/10.1016/S0082-0784(88)80237-6 